\title{
Quality of Life and its Determinants after Stroke in Elderly Patients
}

\author{
Sara A.Sayed 1, Ayman Hassan El-Sudany2, Heba Y. Kamel 1, Manar M. Adel 1, and Sarah A. \\ Hamza1 \\ 1 Geriatric Medicine\& Gerontology department, Faculty of Medicine, Ain Shams University, Cairo, Egypt. \\ 2Neurology department, Faculty of Medicine, Ain Shams University, Cairo, Egypt. \\ Correspondence: heba_youssif@yahoo.com
}

\begin{abstract}
Aim: This study was conducted to assess the impact of stroke on quality of life of elderly and to identify the determinant of $\mathrm{QoL}$ in geriatric stroke patients.
\end{abstract}

Methods: A cross sectional study was performed on 100 Patients with history of cerebrovascular stroke at least three months ago. All participants were subjected to complete medical history taking, cognitive assessment: using Mini-Cog and assessment of quality of life by the short form 36 health survey (SF-36) in its Arabic version

Results: The current study revealed that QoL of studied population was low with median score 34 , and the most affected QoL domains were role limitation due to physical health (RLPH) and that QoL was negatively correlated to age, duration, number of comorbidities and depression.

Conclusions: HRQOL of elderly stroke patients is low, physical and emotional health is the mostly affected. Most determinant factor for QoL domains and sub domains was age.

Keywords: Quality of Life, Stroke, Elderly

\section{Background}

Stroke is one of the most common morbidities in elderly all over the world, with studies showing prevalence more than $50 \%$ in elderly individuals $>60$ years ${ }^{(1)}$, by 2050 , the global number of old people (aged $\geq 65$ years) will be greater than the number of young people (aged $<65$ years) for the first time since formal records began (2). This growth in the aged population, together with the influence of aging on stroke, suggests that the incidence and economic cost of this disease will increase ${ }^{(3)}$ Stroke is the main cause of serious, long-term neurologic impairment and functional disability. Depending on the severity, a stroke can leave an individual with residual impairment of physical, psychological, social and cognitive function (4).

An older person needs more assistance in daily living or requires placement in an institution than a younger patient with stroke ${ }^{(5)}$. The dramatic clinical effect of stroke on older patients can be due to changes in the vascular response to stress and injury with increasing age, which can be due to factors such as pre stroke medical and functional status, multiple organ dysfunctions, polypharmacy, and stroke severity ${ }^{(6) .}$ Meanwhile Health was defined in the World Health Organization (WHO) Constitution as "a state of complete physical, mental and social wellbeing and not merely the absence of disease or infirmity" (7). Measuring health related quality of life (HRQOL) in elderly enable them to maintain their mobility, independence, their active contribution to society, and to respond effectively to the challenges of older age and bring an active aging for them (8). Elderly with multiple disorders often experience problems that adversely influence their HRQoL (9). Therefore, investigating HRQoL of the elderly is especially important because health issues limit their independence and ability to engage in life activities. Despite the growing interest in quality of life (QoL) issues in clinical research and practice, little attention has been paid to evaluating systematically the QoL of stroke patients. QoL investigations are useful in gaining a better understanding of patients' reactions to illness and for enhancing supportive care and also for evaluating the efficacy of therapeutic interventions. Although there is an association between neurological deficits and QL, they are not synonymous ${ }^{(10) .}$

So the aim of this study is to assess the impact of stroke on quality of life of elderly and to identify the determinant of QoL in geriatric stroke patients. 


\section{Methods}

A cross sectional study was conducted in Ain shams university hospitals to assess quality of life of elderly patients after cerebrovascular stroke.

One hundred (100) elderly aged 60 years or more patients with history of cerebrovascular stroke at least three months ago.

Patients who were unwilling to participate in the study, patients with neurological deficit preventing them from cooperation in the study, patients with dementia and patients with end organ failure were excluded from the study.

All participants were subjected to complete medical history taking, neurological assessment, cognitive assessment: using Mini-Cog (11), and assessment of quality of life: by the short form 36 health survey (SF36) ${ }^{(12)}$ in its Arabic version ${ }^{(13)}$

The SF-36 Health Survey is a multi-purpose, shortform health survey which contains 36 questions. It yields an eight-scale profile of scores. The SF-36 is a generic measure of health status as opposed to one that targets a specific age, disease, or treatment group. Accordingly, the SF-36 has proven useful in comparing general and specific populations, estimating the relative burden of different diseases including stroke, differentiating the health benefits produced by a wide range of different treatments, and screening individual patients ${ }^{(14) \text {. }}$

The SF-36 contains eight subscales, which are: physical function, role limitations-physical, bodily pain, vitality, general health perceptions, role limitationsemotional, social function, and mental health ${ }^{(12)}$. In the general population, the mean for each summary scale is 50 points with a SD of 10 points. Higher scores indicate a better HRQOL ${ }^{(15)}$.

SF-36 items also represent multiple operational definitions of health, including function and dysfunction, distress and well-being, objective reports and subjective ratings, and both favorable and unfavorable self-evaluations of general health status (16).

\section{Statistical Analysis}

The collected data were coded, tabulated, and statistically analyzed using IBM SPSS statistics (Statistical Package for Social Sciences) software version 22.0, IBM Corp., Chicago, USA, 2013. Descriptive statistics were done for quantitative data as minimum\& maximum of the range as well as mean \pm SD (standard deviation) for quantitative parametric data, median and 1st\& 3rd inter-quartile range for quantitative non-parametric data, while it was done for qualitative data as number and percentage. The level of significance was taken at $\mathrm{P}$ value $<0.050$ to be significant, otherwise is non-significant. The p-value is a statistical measure for the probability that the results observed in a study could have occurred by chance..

\section{Results}

This study was conducted to assess quality of life of elderly after cerebrovascular stroke using SF-36. It was a cross sectional study performed on 100 patients with history of cerebrovascular stroke at least three months ago. Mean age of study population was $64.6 \pm 6.1$ years, males were $(51 \%)$, married $(71 \%)$ and illiterate (77\%).The most prevalent comorbidity was hypertension $(72 \%)$ followed by diabetes $(56 \%)$ and least was thyroid disease $(2 \%)$ and $43 \%$ of the cases had two comorbidities. Left side weakness was the affected side among $52 \%$ of the studied cases and weakness was the most evident neurological deficit on clinical examination $(77 \%)$.

The current study revealed that QoL of studied population was low with median score 34 , and the most affected QoL domains were role limitation due to physical health (RLPH) and role limitation due to emotional problems (RLEP) followed by physical function $(\mathrm{PF})$ then energy/fatigue $(\mathrm{EF})$ then social function $(\mathrm{SF})$ then general health $(\mathrm{GH})$ then pain $(\mathrm{P})$ and the least was emotional wellbeing (EWB) (table1,2).

\section{Discussion}

Strokes affect patients' lives in many different ways, not only physically but also through a range of emotional, psychical, cognitive and social issues. The seriousness of post-stroke physical and mental impairments affects quality of life. As stroke mortality decreases, more patients have to live with multiple handicaps and impairments. And so, improving the quality of life and paying greater attention to rehabilitation is increasingly important. ${ }^{(17)}$ The current study revealed that QoL of studied population was low with median score 34, and the most affected QoL domains were role limitation due to physical health (RLPH) and role limitation due to emotional problems (RLEP) followed by physical function (PF) then energy/fatigue (EF) then social function (SF) then general health $(\mathrm{GH})$ then pain $(\mathrm{P})$ and the least was emotional wellbeing (EWB).

This is supported by the study done by Mahran et al. (2015) to examine the health-related quality of life (HRQOL) in stroke Survivors attending an outpatient rehabilitation clinic, HRQOL was measured by the SF36 and the stroke-specific quality-of-life (SSQOL) scale and found low mean scores of all the eight domains of SF-36 and that the most affected domains of SF-36 were RP and PF (18). Also the study done by Santos et al. (2013) to study functional capacity and and quality of life of elderly people with a history of stroke reported that the elderly people with stroke have their functional status impaired, which affects their quality of life in aspects related to mobility, body image, decision-making capacity and living in the community ${ }^{(19)}$. 
Table (1): Correlation between QoL and age, comorbidities \& duration of stroke

\begin{tabular}{|c|c|c|c|c|c|c|c|c|}
\hline \multirow[t]{2}{*}{ QoL } & \multirow[t]{2}{*}{ Median (IQR) } & \multirow[t]{2}{*}{ Range } & \multicolumn{2}{|c|}{ Age } & \multicolumn{2}{|c|}{ Comorbidities } & \multicolumn{2}{|c|}{ Duration } \\
\hline & & & $\mathbf{r}$ & $\mathbf{P}$ & $\mathbf{r}$ & $\mathbf{P}$ & $\mathbf{r}$ & $\mathbf{P}$ \\
\hline $\begin{array}{l}\text { Physical function } \\
\text { (PF) }\end{array}$ & $20.0(5.0-50.0)$ & $0.0-100.0$ & -0.237 & $0.018 *$ & -0.205 & $0.041^{*}$ & -0.029 & 0.772 \\
\hline $\begin{array}{l}\text { Role limitation due } \\
\text { to physical health } \\
\text { (RLPH) }\end{array}$ & $0.0(0.0-0.0)$ & $0.0-100.0$ & -0.169 & 0.093 & -0.051 & 0.616 & -0.017 & 0.871 \\
\hline $\begin{array}{l}\text { Role limitation due } \\
\text { to emotional } \\
\text { problems (RLEP) }\end{array}$ & $0.0(0.0-100.0)$ & $0.0-100.0$ & -0.214 & $0.032 *$ & -0.140 & 0.163 & -0.020 & 0.844 \\
\hline Energy/fatigue (EF) & $25.0(15.0-50.0)$ & $0.0-100.0$ & -0.162 & 0.107 & -0.216 & $0.031 *$ & -0.009 & 0.927 \\
\hline $\begin{array}{l}\text { Emotional well being } \\
\text { (EWB) }\end{array}$ & $52.0(36.0-64.0)$ & $0.0-96.0$ & -0.029 & 0.775 & -0.354 & $<0.001^{*}$ & 0.010 & 0.921 \\
\hline Social function (SF) & $37.5(12.5-75.0)$ & $0.0-100.0$ & -0.399 & $<0.001 *$ & -0.113 & 0.264 & -0.196 & $0.050 *$ \\
\hline Pain (P) & $48.8(35.0-100.0)$ & $0.0-100.0$ & -0.128 & 0.205 & -0.220 & $0.028 *$ & -0.296 & $0.003 *$ \\
\hline General health (GH) & $47.5(36.3-60.0)$ & $20.0-80.0$ & -0.155 & 0.123 & -0.151 & 0.135 & -0.221 & $0.027 *$ \\
\hline Total & $34.8(26.0-49.2)$ & $7.5-87.6$ & -0.350 & $<0.001 *$ & -0.302 & $0.002^{*}$ & -0.151 & 0.133 \\
\hline
\end{tabular}

Total=100. IOR: Interauartile range. ${ }^{\wedge}$ Snearman correlation* Significant

Table (2): Linear regression models for factors affecting QoL items

\begin{tabular}{|c|c|c|c|c|c|c|}
\hline Items & Factors & B & SE & $\mathbf{P}$ & $95 \%$ CI & R2 \\
\hline \multirow[t]{4}{*}{ PF } & Age & 0.527 & 0.091 & $<0.001^{*}$ & $0.346-0.707$ & \multirow[t]{4}{*}{0.571} \\
\hline & Male & 15.70 & 5.564 & 0.006 & $4.664-26.753$ & \\
\hline & Right Affection & -14.82 & 5.608 & 0.010 & $-25.953-3.691$ & \\
\hline & $\mathrm{DM}$ & -12.36 & 5.629 & 0.030 & $-23.541-1.194$ & \\
\hline RLPH & Male & 25.786 & 5.124 & $<0.001 *$ & $15.617-35.954$ & 0.231 \\
\hline \multirow[t]{3}{*}{ RLEP } & Age & 0.493 & 0.119 & $<0.001 *$ & $0.256-0.730$ & \multirow[t]{3}{*}{0.440} \\
\hline & Male & 20.573 & 9.791 & 0.038 & $1.141-40.006$ & \\
\hline & Mixed Affection & -37.66 & 17.262 & 0.032 & $-71.923--3.401$ & \\
\hline \multirow[t]{2}{*}{ EF } & Age & 0.579 & 0.050 & $<0.001 *$ & $0.479-0.678$ & \multirow[t]{2}{*}{0.656} \\
\hline & Depression & -13.03 & 4.531 & 0.005 & $-22.028--4.046$ & \\
\hline \multirow[t]{3}{*}{ EWB } & Age & 0.979 & 0.041 & $<0.001 *$ & $0.898-1.060$ & \multirow[t]{3}{*}{0.890} \\
\hline & Depression & -22.42 & 3.564 & $<0.001 *$ & $-29.499--15.351$ & \\
\hline & Mixed Affection & -19.63 & 6.258 & 0.002 & $-32.056--7.211$ & \\
\hline \multirow[t]{3}{*}{ SF } & Age & 0.663 & 0.083 & $<0.001 *$ & $0.499-0.828$ & \multirow[t]{3}{*}{0.628} \\
\hline & Duration & -0.186 & 0.076 & 0.017 & $-0.337--0.035$ & \\
\hline & Right Affection & -14.54 & 6.879 & 0.037 & $-28.197--0.889$ & \\
\hline \multirow[t]{3}{*}{$\mathbf{P}$} & Age & 0.897 & 0.074 & $<0.001 *$ & $0.750-1.044$ & \multirow[t]{3}{*}{0.813} \\
\hline & Male & 12.431 & 5.748 & 0.033 & $1.021-23.840$ & \\
\hline & Duration & -0.264 & 0.065 & $<0.001 *$ & $-0.393--0.135$ & \\
\hline \multirow[t]{3}{*}{ GH } & Age & 0.826 & 0.034 & $<0.001^{*}$ & $0.759-0.892$ & \multirow[t]{3}{*}{0.908} \\
\hline & Duration & -0.117 & 0.035 & $<0.001 *$ & $-0.186--0.048$ & \\
\hline & Right Affection & -9.131 & 3.064 & 0.004 & $-15.212--3.050$ & \\
\hline \multirow[t]{3}{*}{ Total } & Age & 0.529 & 0.046 & $<0.001^{*}$ & $0.438-0.620$ & \multirow[t]{3}{*}{0.824} \\
\hline & Male & 11.449 & 3.775 & 0.003 & $3.957-18.942$ & \\
\hline & Mixed Affection & -17.24 & 6.655 & 0.011 & $-30.450--4.032$ & \\
\hline
\end{tabular}

ß: Regression coefficient, SE: Standard error, CI: Confidence interval, *Significant, R2: adjusted coefficient of determination 
quality of life of elderly people with a history of stroke reported that the elderly people with stroke have their functional status impaired, which affects their quality of life in aspects related to mobility, body image, decision-making capacity and living in the community $^{(19)}$.

This reflects the importance of considering improving physical health among stroke patients which may help improving their QOL, and this can guide the health care providers to improve services for those patients. Regarding number of comorbidities, the current study This reflects the importance of considering improving physical health among stroke patients which may help improving their QOL, and this can guide the health care providers to improve services for those patients. Regarding number of comorbidities, the current study showed that there were significant negative correlations between number of comorbidities and total scores of QoL. This agrees with the study done by Dayapoglu and Tan (2010) conducted on a cohort of 70 patients attending the neurology outpatient clinic, Yakutive Hospital, Erzurum to determine the quality of life and its relationship with socio-demographic and medical factors in patients which reported low quality-of-life scores as regard to global quality of life in stroke patients with other comorbidities (20). This may be related to the health status associated with other comorbidities and also the increased treatment costs.

However, this was not found by Carod-Artal et al. (2000) who studied QoL in stroke survivors 1 year after stroke at San Carlos University Hospital in Madrid, Spain and concluded that comorbid conditions, diabetes, hypertension, or other vascular risk factors did not decrease the global QoL ${ }^{(21)}$. Although they did not provide an explanation, the population culture and the healthcare facilities provided for patients with chronic conditions could explain it.

Regarding determinant factors affecting quality life, Age can affect patients' HRQOL, the mean age of study population was $64.6 \pm 6.1$ years and there were significant negative correlations between age, and PF, RLEP, SF and total scores of QoL.

This agrees with the study done by Che Din Normah et al. (2008) and the results showed that there was significant negative correlation between age and physical functioning in stroke patients (22), also the study done by Dayapoglu and Tan (2010) on Patients aged 61 to 71 years had the lowest scores with regard to functional status, wellbeing and general health perception; and the lowest mean score with regard to global quality of life ${ }^{(20)}$. This may, to some extent, be attributed to the effect of age-related functional decline. But this disagrees with the study done by Gunaydin et al. (2011) which suggested that age has no effect on the QoL (23), this may be due to different tool of QoL assessment used which was SSQoL scale. Regarding duration of stroke, the current study revealed that most of the participants had stroke duration of minimum three months and maximum two years with median three months and that there were significant negative correlation between duration of stroke and social function (SF), pain (P) and general health $(\mathrm{GH})$.

This disagrees with Mahran et al. (2015) who found a significant positive correlation between post stroke duration and the physical component of SF-36, wherein a better physical domain was encountered with an increased chronicity of stroke ${ }^{(18)}$. One explanation for this could be that patients with a long duration of the disease were the ones who had better accommodation and coping with the disease. However, a research from Australia found that even though patient had stroke for 5 years, most of the patients have low score of HRQOL (24).

This controversy can be explained by the presence of other factors which affect the recovery of stroke patients such as rehabilitation programs, social support and financial support. Further studies are needed to clarify the effect of these factors on HRQOL in chronic stroke patients. Also, the maximum duration in our study population was two years which was not sufficient enough for full adaptation.

So, in the current study, elderly stroke patients' QoL is low and by doing linear regression analysis for factors affecting domains of QoL, the most determinant factors for total domains of QoL was found to be age, male gender and mixed affection and by studying the sub domains we found that the most determinant factor for $\mathrm{PF}$ is age, male gender, right side affection and DM, while the most determinant factor for RLPH is male gender. Most determinant factor for RLEP is age, male gender and mixed affection, and most determinant factor for EF is age and depression, while for EWB is age, depression and mixed affection. Most determinant factor for SF is age, duration and right side affection, while for $\mathrm{P}$ is age, male and duration and for $\mathrm{GH}$ is age, duration and right affection.

Stroke affects QoL of elderly patients and the most affected domains were role limitation due to physical health and role limitation due to emotional problems.

Most studies reported that physical function was the most affected domain of SF-36 in elderly stroke patients.

Gunaydin et al. (2011) found that the domains of the QoL related with physical function were most affected in elderly patients and the main determinant of the QoL was the functional status ${ }^{(23)}$. He also found that the most affected subscales were physical and emotional role limitations, and physical function. This raises the importance of providing special care to the elderly stroke patients to increase their HRQOL. So, HRQOL in elderly stroke patients is low, and physical and emotional health is the mostly affected so, therefore, assessment of HRQOL in elderly stroke patients is important for better health outcomes.

\section{Conclusion}

Stroke affects Qol of elderly patients and most affected domain were role limitation due to physical health and 
role limitation due to emotional problems. Qol of stroke patients was negatively correlated to depression, age, duration and number of comorbidities. Most determinant factor for QoL domains and sub domains was age. So, HRQOL in elderly stroke patients is low, and physical and emotional health is the mostly affected so, therefore, assessment of HRQOL in elderly stroke patients is important for better health outcomes.

Acknowledgement: This research was supported by Ain Shams University.

Disclosure statement: No potential conflicts of interest were disclosed.

\section{References}

1. Rosamond W, Flegal K, Furie K, et al., Heart disease and stroke statistics-update: a report from the American Heart Association's Statistics Committee and Stroke Statistics subcommittee.Circulation. 2008;117: e25-e146.

2. Powell JL and Cook IG. Global ageing in comparative perspective: A critical discussion. Int. J. Sociol. Soc. Policy. 2009; 29: 388-400.

3. Warlow CP, GijnJV, DennisMS, et al. Stroke: Practical Management 3rd ed. Wiley-Blackwell, Oxford. 2008

4. Tobin C, Hevey D, Horgan NF, Coen RF, Cunningham CJ. Healthrelated quality of life of stroke survivors attending the volunteer stroke scheme. Ir J Med Sci; 2008. 177: 43-47.

5. Di Carlo A, LamassaM, Pracucci G, et al., Stroke in the very elderly: clinical presentation and determinants of 3-month functional outcome: A European perspective. European BIOMED Study of Stroke Care Group. Stroke;1999. 30: 2313-2319.

6. JKammersgaard LP, Jørgensen HS, Reith J, et al., Short- and longterm prognosis for very old stroke patients: Copenhagen Stroke Study. Age Ageing;2004. 33: 149-154.

7. World Health Organization (WHO) Preamble to the Constitution of the World Health Organization as adopted by the International Health Conference, New York; 1964: 19-22.

8. Bowling A Aging well, quality of life in older age. First Edition Maidenhead: Open University Press. 2005

9. Ehryar AH, Ahmad-Nia S. Age-Structural Transition in Iran: Short and Long-term Consequences of Drastic Fertility Swings During the Final Decades of Twentieth Century, presented at the CICRED Seminar on "Age-Structural Transitions: Population Waves, Disordered Cohort Flows and the Demographic Bonus", Paris; 2004: 23-26.

10. Van Knippenberg FCE, de Haes JCJM: The quality of life of cancer patients: A review of the literature. Soc Sci Med; 1985. 20: 8098171.

11. Borson S, Scanlan JM, Watanabe J, et al., Improving identification of cognitive impairment in primary care. International Journal of Geriatric Psychiatry, 2006: 21(4): 349-355.

12. Ware JE Jr, and Sherbourne CD The MOS 36ltem Short-Form Health Survey (SF-36): I. Conceptual framework and item selection. Med Care; 1992: 30(6): 473-483.

13. Alabdulmohsin SA, Coons SJ, Draugalis JR, Hays RD Reliability of an Arabic version of the RAND-36 Health Survey and its equivalence to the US-English version. Med Care; 1998: 36(3):428432.

14. (Tsai C, Bayliss MS, Ware JE SF-36® Health Survey Annotated Bibliography: Second Edition (1988-1996). Boston, MA: Health Assessment Lab, New England Medical Center. 199

15. Ware JE The status of health assessment 1994.Annu Rev Public Health; 1995: 16: 327-354.

16. Ware JJ, Snow KK, Kosinski M et al., SF-36 Health Survey Manual and Interpretation Guide. Boston, MA: New England Medical Center. The Health Institute. 1993

17. Béjot $Y$, Rouaud $O$, Jacquin $A$ et al., Stroke in the very old:incidence, risk Factors, clinical features, outcomes and access to resources-A 22-year population-based study. Cerebrovasc Dis. 2010; 29:111-121.

18. Mahran SA, AbdulrahmanMA, JanbiFS,et al., The health-related quality of life in stroke survivors :clinical, functional, and psychosocial correlate. Egyptian Rheumatology \& Rehabilitation. 2015; 42:188-195

19. Santos NMF, Tavares DMS, Dias FA, et al., Functional capacity and quality of life of elderly people with a history of stroke, ActaScientiarum. Health Sciences Maringá; 2013: 35, 1: 49-57.

20. Dayapoglu N and Tan M, Quality of life in stroke patients. Neurol India;2010: 58: 697-701

21. Carod-Artal J, Egido JA, González JL et al., Quality of life among stroke survivors evaluated 1 year after stroke: experience of a stroke unit. Stroke; 2000: 31:2995-3000.

22. Che Din N, Ahamat MH, Mukahar R et al.,( Health-Related Quality Of Life in stroke patients, Prosiding Seminar Sebumi 2008. Universitas Indonesia, Jakarta

23. Gunaydin R, Karatepe AG, Kaya T et al., Determinants of quality of life $(\mathrm{Q} L \mathrm{~L})$ in elderly stroke patients: A short-term follow-up study, Archives of Gerontology and Geriatrics; 2011: 53: 19-23.

24. Paul SL, Sturm JW, Dewey HM, et al., (Long term outcome in the North East Melbourne stroke incidence study:predictor of quality of life at 5 years after stroke. Stroke, 2005: 36: 2082- 